\title{
Ciencia y ficción. Notas sobre el escepticismo epistemológico del Quijote
}

\author{
FÉLIX SCHMELZER*
}

\begin{abstract}
Resumen
El presente trabajo pretende analizar la representación del saber científico en el Quijote de Cervantes, basándose en varios pasajes que subrayan los conocimientos científicos de don Quijote. Se constata que la novela revela una sutil crítica de las ciencias en cuyo fondo está un profundo escepticismo epistemológico frente a la arbitrariedad de nuestros conceptos del mundo. La caracterización de don Quijote como científico incluso permite deducir que sufre un doble daño de lectura (caballeresco y científico) y que Cervantes, por tanto, considera la propia ciencia como ficción, un punto de vista muy moderno.
\end{abstract}

Palabras clave: Cervantes; Quijote; Ciencia; Ficción; Epistemología.

Title: Science and Fiction. On Don Quijote's Epistemological Skepticism

\begin{abstract}
The present work seeks to analyze the representation of scientific knowledge in Cervantes' Quixote, focusing on various passages that underline the scientific expertise of don Quixote himself. It is shown that the novel contains a subtle critique of science, based on an epistemological skepticism with regard to the arbitrariness of our world concepts. The characterization of don Quixote as a man of science even permits deducting that he suffers from a 'double mental damage', caused by the lecture of both books of cavalry and science. Cervantes thus would consider science to be fiction, a very modern point of view.
\end{abstract}

Keywords: Cervantes; Quixote; Science; Fiction; Epistemology. 
En los últimos años han surgido varios estudios que analizan el Quijote desde la perspectiva científico-histórica, una obra pionera en este contexto es La ciencia y el Quijote (2005), dirigido por José Manuel Sánchez Ron ${ }^{1}$. En el marco de este nuevo enfoque se considera la novela monumental de Cervantes un auténtico documento científico-histórico que refleja la visión del mundo de aquel entonces. Generalmente, esos estudios detectan y reconstruyen los diferentes saberes científicos incluidos implícita o explícitamente en el Quijote. Los resultados son herramientas hermenéuticas útiles para llegar a una comprensión más profunda de la obra en sus particulares contextos históricos. Un lector de hoy debería saber, por ejemplo, cómo se componía el universo a inicios del siglo XVII porque muchos pasajes, sobre todo algunos de los discursos eruditos de don Quijote, hacen referencia a la cosmología de la época, que todavía es esencialmente aristotélica; asimismo, la astronomía es de una importancia central, dado que los protagonistas de la obra miran e invocan los cielos continuamente. También son relevantes algunas disciplinas que hoy día más bien llamaríamos seudo-ciencias, como la astrología, hermana de la astronomía, que en su forma popular y supersticiosa («astrología judiciaria») cae en descrédito a lo largo del siglo XVI, una discusión que a su vez resuena en el famoso episodio del «mono adivino» ${ }^{2}$. Son, igualmente, significativas la cosmografía, la náutica, la física, la medicina, el arte militar, etc. ${ }^{3}$. Sin duda, la novela contiene en sí una curiosa enciclopedia de saberes que la convierten en una fuente valiosa para el historiador de las ciencias. Ahora bien, al lado de la pregunta de qué disciplinas son inherentes a la obra, también es interesante cómo Cervantes las representa. Si leemos el Quijote con esta pregunta en mente, la novela revela una sutil crítica de las ciencias, y del saber científico en conjunto, en cuyo fondo está un profundo escepticismo epistemológico frente a la arbitrariedad de nuestros conceptos del mundo. Eso es visible, en particular, en varios pasajes que subrayan los conocimientos científicos de don Quijote.

\section{EL CABALLERO UNIVERSAL}

De acuerdo con el afán de educación enciclopédica humanista, don Quijote es representado como un caballero versado en todas las artes y ciencias. A lo largo de la novela, se hace obvio que no solo leyó todos los libros de

1. En el capítulo preliminar, el mismo Sánchez Ron constata la falta de estudios científicohistóricos del Quijote y declara que «nunca hasta ahora se había intentado relacionar el inmortal y ejemplar libro de Cervantes con el conjunto de la ciencia, la medicina y la técnica de su tiempo» (p. 7).

2. Quijote, II, 25.

3. En La ciencia y el Quijote se incluyen las siguientes disciplinas: aritmética, geometría, astronomía, astrología, cosmografía, geografía, náutica, ingeniería, minería, metalurgia, historia natural, medicina, además hipología (el estudio del caballo doméstico) y alimentación. Una descripción más detallada de los saberes científicos del Siglo de Oro español se encuentra en la Historia de la ciencia y de la técnica en la Corona de Castilla (III. Siglos XVI y XVII), editada por López Piñeiro. 
caballería, sino también los relevantes tratados científicos de su época. Una primera idea de su educación científica nos la da el capítulo 12 del primer libro: un cabrero empieza a contarle la historia del recién fallecido «pastor estudiante llamado Grisóstomo» con las siguientes palabras: «Principalmente decían que sabía la ciencia de las estrellas, y de lo que pasan allá en el cielo el sol y la luna, porque puntualmente nos decía el cris del sol y la luna» (104). No soportando el habla vulgar del cabrero - cris fue una forma popular de eclipse- don Quijote le interrumpe bruscamente para corregirle: «Eclipse se llama, amigo, que no cris, el escurecerse esos dos luminares mayores» (104); la actitud erudita de don Quijote frente a la supuesta ignorancia del vulgo es un tema recurrente en la obra ${ }^{4}$. Su caracterización como científico tiene un punto culminante en el capítulo del «Caballero del Verde Gabán» (II, 18). Él y Sancho se encuentran en la casa del noble don Diego de Miranda, que no sabe si tenerle «por loco o por cuerdo» a don Quijote y por ello pide a su hijo Lorenzo que le entreviste. Poniéndole a prueba, Lorenzo le pregunta qué ciencias ha estudiado, y don Quijote responde: «la de la caballería andante». «No sé qué ciencia sea ésa», contesta el interlocutor, así que el sospechoso de locura prosigue con una definición curiosa:

Es una ciencia $[\ldots]$ que encierra en sí todas o las más ciencias del mundo, a causa que el que la profesa ha de ser jurisperito y saber las leyes de la justicia distributiva y conmutativa, para dar a cada uno lo que es suyo y lo que le conviene; ha de ser teólogo, para saber dar razón de la cristiana ley que profesa, clara y distintamente, adonde quiera que le fuere pedido; ha de ser médico, y principalmente herbolario, para conocer en mitad de los despoblados y desiertos las yerbas que tienen virtud de sanar las heridas, que no ha de andar el caballero andante a cada triquete buscando quien se las cure; ha de ser astrólogo, para conocer por las estrellas cuántas horas son pasadas de la noche y en qué parte y en qué clima del mundo se ha1la; ha de saber las matemáticas, porque a cada paso se le ofrecerá tener necesidad de ellas; y dejando aparte que ha de estar adornado de todas las virtudes teologales y cardinales, descendiendo a otras menudencias, digo que ha de saber nadar como dicen que nadaba el peje Nicolás, o Nicolao, ha de saber herrar un caballo y aderezar la silla y el freno, y, volviendo a lo de arriba, ha de guardar la fe a Dios y a su dama; ha de ser casto en los pensamientos, honesto en las palabras, liberal en las obras, valiente en los hechos, sufrido en los trabajos, caritativo con los menesterosos y, finalmente, mantenedor de la verdad, aunque le cueste la vida el defenderla. De todas estas grandes y mínimas partes se compone un buen caballero andante; porque vea vuesa merced, señor don Lorenzo, si es ciencia mocosa lo que aprende el caballero que la estudia y la profesa, y si se puede igualar a las más estiradas que en los ginasios y escuelas se enseñan (682-683).

4. Aquí resuena el tópico renacentista «el vulgo y el sabio», recurrente en la obra de Cervantes en general (ver Castro, 1972, pp. 213-215). Lo característico del Qujote es que vuelve al revés el esquema habitual del tópico: la sabiduría popular o «sana razón de campesino» (Alonso, 2003, p. 14) representada por Sancho siempre se revela superior a la ingenuidad erudita de don Quijote. 
Resuena aquí el antiguo tópico de las armas y las letras, muy divulgado en la época de Cervantes en todo tipo de textos y géneros literarios, según el cual los grandes capitanes y príncipes conocen a fondo todas las ciencias ${ }^{5}$. La composición de disciplinas es particularmente interesante: la primera parte de la cita muestra que don Quijote concibe la «caballería andante» como una ciencia universal que incluye los estudios más prestigiosos de la época: jurisprudencia, teología, medicina $\mathrm{y}$, además, las matemáticas, que también son de alta estima en aquel entonces ${ }^{6}$. Por estar relacionadas con saberes y facultades más bien vulgares como «saber herrar un caballo» o «nadar como el peje Nicolás», estas disciplinas son, en cierto sentido, despojadas de su valor real y reducidas a lo absurdo. El pasaje se burla, además, de ciertos discursos seudo-científicos de la época, en la que muchos autores intentaban aumentar el prestigio de su disciplina al concebirla como «ciencia» aunque en verdad se tratara de una artesanía o arte mecánica. Un ejemplo curioso es el Libro de las grandezas de la espada (1600) de Luis Pacheco, un tratado popular que Cervantes conocía, donde el autor intenta, con tono patético, elevar la esgrima (designada «verdadera destreza») al rango de una ciencia por fundarla en aritmética, geometría y filosofía natural ${ }^{7}$. Desde la perspectiva de hoy, esta obra tiene un efecto cómico, y parece que Cervantes detectó ya en su tiempo la comicidad involuntaria de ese tipo de discurso.

En un nivel más general, la figura de don Quijote aparece como una reproducción grotesca del uomo universale renacentista: el 'caballero universal'. Debido a la mezcla particular de saberes y disciplinas, y también porque es

5. Un caso ejemplar de la Antigüedad, citado con mucha frecuencia en la literatura española del Siglo de Oro, es la erudición de Alejandro Magno, cuyo educador fue nada menos que Aristóteles (ver Plutarco, Vidas paralelas. Alejandro-César). El 'sabio capitán' a su vez sirve de modelo para el 'sabio príncipe', tal como aparece en los espejos de príncipes de la época.

6. El alto prestigio de las matemáticas se explica por el hecho de que estas disciplinas no solo forman la base de la nueva filosofía natural de carácter pitagórica que se desarrolla en aquel entonces (y que Galileo resume en su famoso dicho que 'el libro de la naturaleza está escrito en caracteres matemáticos'), sino también porque son indispensables para todas las artes mecánicas necesarias para el estado (arquitectura, ingeniería, fortificación, náutica, etc.). La gran necesidad de estas disciplinas para el imperio español se manifiesta en la fundación de la Real Academia de Matemáticas por Felipe II en 1582, una de las primeras academias científicas de la época moderna.

7. Cito un pasaje del capítulo preliminar («Los fundamentos sobre que está fundada la verdadera destreza»-el autor designa la esgrima como «verdadera destreza»-): «está fundado este maravilloso edificio de la destreza sobre tales y tan fuertes fundamentos que ni el rigor del tiempo la consumirá ni jamás se envejecerá, ni perderá de su ser un punto. Porque de cualquiera parte que la miréis, la hallaréis que estriba sobre las sólidas murallas de las ciencias, las cuales le ayudan con la verdad que cada una por sí tiene, y le favorecen con certeza, y la hacen más fuerte, añadiendo fuerza a fuerza. De tal suerte que si la matemática en si tiene certeza y verdad, la destreza se muestra por ella, y la fortalece con sus demostraciones. Y si la arismética en si tiene verdad y certeza, la de la destreza se acompaña con ella porque trata de cuenta y razón. Y si la filosofía natural nos descubre y manifiesta muchos secretos, ella misma declara los que la destreza tiene» (fol. 2r). Las ideas particulares de Pacheco resuenan también en el siguiente capítulo (XIX) de la segunda parte, donde don Quijote y Sancho se encuentran con «uno de estos a quien llaman diestros» que, después de haber derrotado a un adversario, les explica «las excelencias de la espada, con tantas razones demostrativas y con tantas figuras y demostraciones matemáticas, que todos quedaron enterados de la bondad de la ciencia» (696). 
demasiado «universal», su erudición es de poco crédito. Volviendo al contexto del capítulo, es sugerente que sus declaraciones finalmente convencen a Lorenzo de que está completamente loco. Obviamente, el saber científico, de alguna manera, forma parte de esa locura.

\section{DON QUIJOTE COMO COSMÓGRAFO: EL EPISODIO DEL «BARCO ENCANTADO»}

Al lado de su educación enciclopédica, en varios lugares de la novela son subrayados los saberes específicos de don Quijote. En este contexto se descubre que la obra de Cervantes no es solo una parodia de los discursos (seudo-)científicos contemporáneos, sino que además pone en duda la visión científica del mundo en general, es decir, la destacada convicción de poder explicar la realidad a través del concepto. Se trata de una crítica sutil que es inherente, entre otros, al capítulo del «barco encantado» (II, 29), donde destacan los conocimientos cosmográficos y náuticos de don Quijote. He aquí un recuento breve de lo que ocurre: después de un largo camino, él y Sancho llegan al río Ebro, donde encuentran un pequeño barco atado en la orilla, y pasa lo de siempre: un escenario anclado en la realidad deja caer a don Quijote en un tópico plantado en la literatura caballeresca; se obsesiona con la idea de que algún caballero o noble debe estar en gran peligro y que el simple barco es un barco encantado que está ahí para poder salvarle, de acuerdo con el maravilloso viaje de Palmerín ${ }^{8}$. En contra de las advertencias de Sancho («a mí me parece que este tal barco no es de los encantados, sino de algunos pescadores de este río», 773), no puede resistirse a las tentaciones de una aventura inminente, así que los dos se embarcan. El barco se va apartando poco a poco de la ribera y, apenas recorridos unos metros, don Quijote se deja llevar por otro tópico, el del viaje marítimo, y declara:

Pero ya habemos de haber salido y caminado por lo menos setecientas o ochocientas leguas; y si yo tuviera aquí un astrolabio ${ }^{9}$ con que tomar la altura del polo, yo te dijera las que hemos caminado: aunque o yo sé poco

8. Un glorioso caballero que a su vez viaja en un barco mágico; su viaje es un tópico de la literatura caballeresca. En este contexto, el capítulo del «barco encantado» remite al capítulo 56 del primer libro del Palmerín de Inglaterra (1547), famosa novela de Francisco de Moraes (ver Riquer, 2003, pp. 193-194).

9. Se trata de un aparato medidor para los ángulos del cielo. Inventados ya en la Antigüedad, los astrolabios se utilizaban frecuentemente para la navegación entre los siglos XV y XVII. «El astrolabio se hace en esta manera: en el medio de una tabla redonda, que sea de metal o madera y por todas partes igual y del grueso de un dedo, se tomará un punto A, en el cual, puesta la una punta del compás con la otra se señalará un círculo, el mayor que pudiere recebir la dicha tabla. Y dentro de este círculo se señalarán otros dos, que el segundo diste del primero por el ancho de un grano de trigo, y el tercero diste del segundo el doble que el segundo del primero» (Zamorano, Compendio arte de navegar, 1588, fol. 13r, en Dicter). 
o ya hemos pasado o pasaremos presto por la línea equinoccial ${ }^{10}$, que divide y corta los dos contrapuestos polos en igual distancia (774).

Sancho no entiende lo que dice, y don Quijote se ríe de él -otra vez se revela una cierta arrogancia erudita frente a la ignorancia del vulgo-. Explica a Sancho que, una vez pasada la línea equinoccial, todos los piojos se mueren, y le pide que busque en su cuerpo cosas vivas. El escudero se muestra escéptico, y su amo prosigue su exposición con una gama de términos técnicos relativos a la cosmografía y la náutica ${ }^{11}$ :

Haz, Sancho, la averiguación que te he dicho, y no te cures de otra, que tú no sabes qué cosa sean coluros ${ }^{12}$, líneas, paralelos, zodíacos, eclípticas, polos, solsticios, equinoccios, planetas, signos, puntos, medidas, de que se compone la esfera celeste y terrestre; que si todas estas cosas supieras, o parte de ellas, vieras claramente qué de paralelos hemos cortado, qué de signos visto y qué de imágenes hemos dejado atrás, y vamos dejando ahora (775).

La acumulación de tecnicismos esboza, de manera paródica, la imagen científica del mundo del Renacimiento. El universo en su conjunto aparece como una entidad completa-mente dividida, cortada y medida (la mayoría de los términos se refiere a la medición geométrica del cielo).

Es sugerente leer el pasaje en su contexto histórico: en la época de Cervantes, la cosmografía y la náutica -que se basan, a su vez, en la astronomía- llegan a tener un alto grado de sofisticación y precisión; gracias a esas disciplinas, el hombre es capaz de orientarse con seguridad en cualquier parte del mundo. La nación española tuvo el predominio en ese ámbito durante el siglo $\mathrm{XVI}^{13}$, y los tratados contemporáneos reflejan la auto-conciencia de un imperio cuyos pilotos rodean el globo con regularidad. El orgullo respecto a las conquistas de la ciencia que caracteriza el Renacimiento en general es muy obvio en esos escritos en particular, ya que se sabe que los conocimientos de los antiguos han sido superados definitivamente. Para dar una idea más concreta de esa auto-conciencia científica, cito del «Proemio» del Arte de navegar de Pedro de Medina (1545), el más divulgado tratado náutico de su tiempo $^{14}$ (que Cervantes, sin duda, conocía):

10. 'El ecuador'.

11. Nótese que el siguiente rechazo de Sancho revela la estructura argumentativa de siempre; en el famoso capítulo 8 se lee: «no estás cursado en esto de las aventuras: ellos son gigantes» (75). La supuesta ignorancia de Sancho se revela tanto en el nivel de la literatura caballeresca como en el nivel de la literatura científica.

12. Para estos términos técnicos en su significado histórico remito al Dicter. Ver también el estudio científico-histórico del capítulo del «barco encantado» de Navarro Brotons (2005).

13. Gracias a los historiadores de las ciencias, la 'leyenda negra' según la cual el país no participaba en la Revolución Científica se ha vuelto últimamente en cierto sentido al revés, al menos en el ámbito de las ciencias aplicadas.

14. Fue editado en toda Europa en cinco idiomas durante los siglos XVI y XVII. La obra se divide en ocho libros y, como era habitual, parte de los conocimientos básicos de astronomía (libro I). 
¿quién basta a decir una sutileza tan grande que un hombre con un compás y unas rayas señaladas en una carta sepa rodear el mundo, y sepa de día y de noche a donde se ha de allegar y de donde se ha de apartar, y cuánto ha de andar a una parte y a otra, y que acierte a caminar por una cosa tan larga y espaciosa como es la mar, donde ni hay camino ni señal dél? [...] ¿Y quién basta a decir tan gran sutileza que con un instrumento redondo del tamaño de un palmo, llamado astrolabio, se mida la redondez del cielo, siendo tan grande que el entendimiento del hombre no lo puede alcanzar, y con este se toma el altura del sol, pasándolo por muy delicado y sutil lugar, siendo mayor muchas veces que toda la tierra y la mar, y se sepa cuánto está allegado o apartado de nos, $\mathrm{y}$ asimismo se tome el altura de las estrellas, y que esto nos enseñe y guíe tan cierto que no falte punto? También, ¿quién podrá decir la sutileza y primor de la brújula o aguja de marear, la cual, con tanto papel como la mitad de la mano, y con ciertas rayas señaladas que denotan los vientos, y con un poco de hierro puesto en ella, se haga un instrumento, y esta se mueva por sí con sola virtud natural que una piedra le influye, y con su propio movimiento, sin que nadie le mueva, ella por sí enseñe dónde es el levante y dónde el poniente, y el septentrión y el mediodía, y semejantemente todos los treinta y dos vientos que tiene la navegación? [...] ¡Oh bien dichosa nación española, tan señalada en el mundo, que ni peligro de muerte ni temor de hambre y sed, ni de otros innumerables trabajos, han bastado a quitar que, por mares nunca navegadas y tierras incógnitas y nunca oídas, esforzados con la fe, habéis rodeado el mundo! Cosa es tan grande que los antiguos ni la vieron ni pensaron, antes por imposible la tuvieron (fols. IIIr-IVr).

Este elogio de la excelencia del arte de navegar revela una actitud científica muy segura de sí misma. De manera ejemplar, se aclara la imagen del mundo al fondo de la prosa científica renacentista (podría citarse otros ejemplos ${ }^{15}$ ): se trata de un mundo cuantificable y dominable por la ciencia y la técnica, un mundo que, en términos generales, encaja con el concepto científico de él. En este sentido, durante el Renacimiento, el afán descubridor que revela la cita va acompañado de un llamativo optimismo epistemológico. El hombre que ha medido el cielo, la tierra y las aguas y cree incluso conocer la estructura del universo entero está convencido de que ya no hay límites para su entendimiento y que será capaz de descifrar todos los secretos. Me permito complementar la cita anterior con un pasaje del Diálogo de la dignidad del hombre de Pérez de Oliva para captar ese espíritu científico tan optimista (al que el Quijote se opone decisivamente):

Rodeamos la tierra, medimos las aguas, subimos al cielo, vemos su grandeza, contamos sus movimientos y no paramos hasta Dios, el cual no se nos esconde. Ninguna cosa ay tan encubierta, ninguna ay tan apartada, ninguna

El resto del libro es más bien de orientación práctica: trata los fenómenos del mar (II), meteorología (III), los modos de hallar la altura del sol (IV), cómo hallar la altura del polo por la estrella polar (V), la brújula (VI), la luna y el calendario (VII) y los días y sus desigualdades (VIII).

15. Ver, por ejemplo, la Suma de geografia de Martín Fernández de Enciso (Sevilla, 1519). 
ay puesta en tantas tinieblas, do no entre la vista del entendimiento humano para ir a todos los secretos del mundo; hechas tiene sendas conocidas, que son las disciplinas, por do lo pasea todo (153).

De acuerdo con este pasaje del Diálogo, la navegación a tierras desconocidas se convierte en metáfora de la fe incondicional en el progreso científico y las capacidades supuestamente ilimitadas del entendimiento humano a lo largo de la Revolución Científica. Un famoso ejemplo es la portada de la Instauratio Magna, obra principal e inacabada de Francis Bacon (de la que forma parte el Novum Organum): un galeón va pasando por las míticas columnas de Hércules que marcan el estrecho de Gibraltar hacia el Atlántico. Bacon pensaba que su método empírico significaba una brecha parecida en el ámbito de las ciencias naturales, es decir que había llegado el tiempo de dejar atrás las falsas y limitadas ideas antiguas y llegar a un conocimiento verdadero de las leyes naturales. Desde la perspectiva científico-filosófica actual, Pérez de Oliva y Bacon son representantes de un cientificismo ingenuo; sabemos que el conocimiento verdadero y completo del mundo al que aspiraban es un ideal inalcanzable debido a nuestros límites cognitivos, y parece que Cervantes ya lo intuía ${ }^{16}$. Una lectura del Quijote es, de hecho, un antídoto eficaz contra el idealismo científico renacentista.

Volviendo al episodio del barco, es muy significativo que los dos protagonistas naufragan miserablemente poco tiempo después de la exposición erudita de don Quijote. Es obvio que sus conocimientos cosmográficos y náuticos no le han servido mucho; en vez de dar orientación, le han llevado a una desorientación total. Es decir, la ciencia no ha descubierto el ser verdadero de la realidad, sino que ha bloqueado la vista a ella, y aquí, precisamente, surge la dimensión epistemológica de la novela.

\section{LA DIMENSIÓN EPISTEMOLÓGICA}

Un estudio de la aventura del barco encantado en un contexto científicohistórico indica que don Quijote, de hecho, sufre de un doble daño de lectura. La imagen del barco provoca en él un engaño caballeresco (un caballero compañero está en peligro y hay que salvarle inmediatamente) y, al mismo tiempo, un engaño científico. Dicho de otra manera, su lucha fantástica contra gigantes que son en realidad molinos de viento -en otro famoso capítulo- se corresponde con su idea de surcar la inmensidad de los océanos, seguramente guiado por los conocimientos de la cosmografía y la náutica, cuando en realidad se encuentra en un pequeño barco en un pequeño río y está a punto de

16. Cervantes no podía conocer la obra principal de Bacon, que se publicó por primera vez en 1620, pero sin duda detectaba la fe extraordinaria (y ciega) en el progreso científico característica de la época en general (y que culminaría en dicha obra). 
naufragar. Los discursos eruditos de don Quijote indican, pues, que no solo ha leído demasiados libros de caballería ${ }^{17}$, sino también demasiados tratados científicos, con un efecto confundidor comparable. Aunque habría que verificar esa tesis con más ejemplos textuales, creo que la caracterización de don Quijote como científico permite deducir que Cervantes considera la propia ciencia como literatura, es decir, como ficción, un punto de vista, de hecho, muy moderno ${ }^{18}$.

Hay otros pasajes que subrayan esa idea de la ciencia como ficción, por ejemplo cuando don Quijote y Sancho montan a Clavileño, el caballo volador, para luchar contra el gigante Malambruno (II, 41). En pleno «vuelo», don Quijote exclama:

Sin duda alguna, Sancho, que ya debemos de llegar a la segunda región del aire, adonde se engendra el granizo y las nieves; los truenos, los relámpagos y los rayos se engendran en la tercera región, y si es que de esta manera vamos subiendo, presto daremos en la región del fuego, y no sé yo cómo templar esta clavija para que no subamos donde nos abrasemos (860).

Otra vez, el engaño caballeresco va acompañado por el engaño científico. En este discurso, don Quijote refiere conceptos básicos de la cosmología y física aristotélica ${ }^{19}$ y se imagina el caballo volando por las diferentes regiones o esferas elementales de la zona sublunar. Ya han subido a la esfera del aire, que a su vez se divide en distintas subregiones en donde se producen los mencionados fenómenos meteorológicos, y están al punto de llegar a la del fuego. También aquí, el concepto científico es encasquetado, de manera inapropiada, a una realidad completamente distinta: el caballo es de madera y no se mueve. Llama la atención, además, que, como en el pasaje del barco, el excurso científico implica de una expansión espacial, lo que apunta a un anhelo cósmico, esencialmente renacentista, del caballero andante. La ciencia aparece de esta manera como un medio para escapar de la estrechez del mundo; inútil y en vano, como descubre la novela una y otra vez.

En conjunto, ambos pasajes pueden interpretarse como una parodia del hombre científico obsesionado que quiere imponer su concepto del mundo con toda fuerza y no se da cuenta de que no encaja con la realidad ${ }^{20}$. Que

17. Habría que añadir, aunque sean de menor importancia, novelas pastoriles, sentimentales, etc.

18. Hans-Magnus Enzensberger, por ejemplo, poeta contemporáneo alemán, explica en Die Elixiere der Wissenschaft que la ciencia es esencialmente poética, incluso más que la poesía misma. Se refiere en este contexto, sobre todo, a la astrofísica y las matemáticas, donde surgen teorías y conceptos fantásticos como «agujeros negros», «espuma cuántica», «efecto mariposa», etc.

19. El pasaje remite a la división del cosmos en la zona sublunar (la tierra) y la zona supralunar. La zona sublunar se divide a su vez en cuatro regiones elementales -tierra, agua, aire y fuego-. En la región del aire se producen los fenómenos meteorológicos mencionados. Aristóteles desarrolla esas teorías con más detalle en Acerca de la generación y la corrupción, Acerca del cielo y Meteorológicos.

20. Maravall (2006, p. 142) indica que la figura del Quijote refleja ciertos tipos de locura o irracionalidad frecuentes en la época de Cervantes: «Cervantes, doloridamente, se interroga por esos hombres que ve junto a él, por esos españoles de su tiempo que [...] aparecen en su conducta des- 
los conceptos de realidad y la realidad misma son cosas distintas y que los primeros son, en cierto grado, arbitrarios, es otro punto de vista muy moderno de la obra cervantina ${ }^{21}$. En ese sentido, se puede constatar en la novela un escepticismo epistemológico que se opone decisivamente a la visión renacentista.

\section{ALGUNAS REFLEXIONES CONCLUSIVAS}

La noción de la ciencia como ficción inherente al Quijote es atrevida en la época de Cervantes, cuando se suponía que el saber científico nos transmite una imagen verdadera y objetiva de la realidad. Desde la perspectiva actual, al contrario, podemos subrayar esa noción, con ciertas restricciones al me$\operatorname{nos}^{22}$. El escepticismo epistemológico sería, por tanto, uno de los elementos universales de la obra cervantina que se refleja, quizá, mejor en la conciencia de un lector del siglo XX o XXI que en la de un lector del siglo XVII. Se sabe hoy que las estrategias narrativas ${ }^{23}$ y retóricas ${ }^{24}$ son componentes esenciales del discurso científico, por ejemplo, y que la verdad científica no es 'pura' ni 'desnuda', sino que está inseparablemente entretejida con estos elementos. Además, desde la perspectiva de la filosofía de las ciencias, se ha subrayado en las últimas décadas que el fondo del saber científico es necesariamente metafórico, es decir que cualquier teoría científica tiene que fundarse necesariamente en ciertos presupuestos de la realidad que no son en sí mismos demostrables ${ }^{25}$. La fantasía, pues, es un elemento decisivo de la

viados de caminos de racionalidad. Sólo en conexión con estas circunstancias se llega a comprender lo que don Quijote significa en la anormalidad de su comportamiento». En palabras de Spitzer (1955, p. 131), la «locura» de don Quijote «no es más que un reflejo de la general locura humana, sobre la que libremente se ha colocado Cervantes». Siguiendo esas ideas, también la 'obsesión científica' puede ser interpretada como una perturbación o demencia histórica que representa la crisis espiritual de la Modernidad.

21. Desde La estructura de las revoluciones cientificas (1962), obra memorable del filósofo de las ciencias Thomas S. Kuhn, se suele constatar que el desarrollo científico se caracteriza más bien por cambios de paradigma (y Kuhn subraya que un paradigma no es necesariamente más verdadero que otro) que por un acercamiento gradual a la verdad, y cada paradigma tiene sus propios conceptos de la realidad.

22. Hay que diferenciar: no se puede equiparar literatura y ciencia por completo, como suelen hacer algunos seguidores de la tesis literature and science, porque al contrario de la literatura la ciencia es capaz de producir un conocimiento verdadero y demostrable (aunque no sea tan absoluto y objetivo como soñaban los pioneros de la visión científica del mundo). Por otra parte, ciencia es «ficción» en el sentido de que no puede excluir el elemento fantástico o creador del proceso de la formación de una teoría. En este contexto, el estudio de los aspectos literarios o, en términos más generales, lingüísticos de las ciencias sirve para un conocimiento más profundo de nuestras capacidades y límites cognitivas.

23. Ver la obra pionera de Beer, 1983.

24. Ver en este contexto Schmelzer, 2015.

25. Ver Blumenberg, 1960; Grassi, 1980. Podría decirse que estos autores revivifican la noción aristotélica de los archai, aquellos primeros principios (no en sí mismos demostrables) sobre los que se funda cualquiera teoría científica. 
ciencia, Einstein ha insistido en este punto, y creo que el autor del Quijote lo intuía. Como en tantos otros, también en este contexto se muestra la (pos) modernidad de la novela cervantina.

Podemos concluir que Cervantes tenía una sensibilidad peculiar frente a la arbitrariedad de conceptos del mundo, ya sean científicos o literarios. Esa sensibilidad está arraigada en su persona, pero también en su tiempo. Vivía en una época de transición que el historiador de las ciencias Alexandre Koyré llamaba «del mundo cerrado al universo infinito», y es probable que el 'espacio libre', tal vez solo palpable por la mente humana entre una imagen del mundo y otra, genera la conciencia de la futilidad de esos conceptos. El hombre renacentista, en todo su afán científico y descubridor, vivía todavía en la comodidad de la cosmología aristotélico-ptoloméica, es decir, en un abarcable universo esférico, con la tierra en el centro y Dios (el primer motor inmóvil) al borde ${ }^{26}$. Pero, a lo largo del siglo XVII, será echado de la casa familiar en que había vivido durante siglos e incluso milenios. Se impondrá un nuevo concepto, la visión heliocéntrica, que a su vez se transformará en el universo newtoniano a finales del siglo: una máquina infinita, regida solo por las leyes de causa y efecto, sin la necesidad teórica de Dios ${ }^{27}$. La tierra se vuelve un punto nulo en la inmensidad de un cosmos secularizado (aquí está el gran dilema metafísico de la Modernidad).

Cervantes todavía no podía conocer este desarrollo en su totalidad, por supuesto, y tampoco se sabe en qué medida estaba al tanto de las discusiones cosmológicas de su tiempo ${ }^{28}$, pero eso es de menor importancia. Lo que cuenta, creo, es que sentía ese 'espacio libre', que captaba intuitivamente que un conocimiento seguro y objetivo del mundo no es posible, y que tenía, además, la sensibilidad psicológica para saber que el hombre, en épocas de inseguridad, tiende a aferrarse al pasado. Esas son verdades intemporales de nuestra existencia terrenal. En este sentido, el caballero andante es más que una mera parodia: deviene en símbolo del ser humano en busca de una seguridad de conocimiento en un mundo ideal, mientras que su mundo real

26. La obra de Copernico (De revolutionibus orbium coelestium, 1543) se dio a conocer en España a partir de la segunda mitad del siglo XVI, pero como en el resto de Europa se consideraba su teoría más bien una especulación matemática, y no una cosmología nueva. Además, el universo copernicano conserva los rasgos generales de la cosmología aristotélica (todavía es un universo esférico abarcable; en principio cambian solamente las posiciones de la tierra y del sol).

27. Es redundante decir que también esa imagen de una máquina infinita es histórica. La cosmovisión del siglo XX revela un universo en expansión continua, nacido en una explosión inicial, y cuya estructura remite a una red o telaraña dinámica.

28. Tres décadas después de la publicación de la obra de Copérnico, el astrónomo Jerónimo Muñoz dio un golpe más fuerte a la cosmología aristotélica con su Libro del nuevo cometa (1573), bastante difundida en su tiempo, donde constata que el supuesto cometa que fue visible en 1572 en todo Europa era un fenómeno de la zona supralunar y que los cielos, por tanto, no son inmutables y eternos (como pensaba Aristóteles), sino que sufren de corrupción y cambio. En 1610, Galileo publica sus primeras observaciones telescópicas en Siderus nuncius... No sé si Cervantes conocía estos textos o no, pero como hombre de su tiempo sentía seguramente que el monumento aristotélico, y toda la cosmovisión que traía consigo, estaba desmoronándose poco a poco. 
está en continua convulsión. Este mundo ideal solo existe en los libros, y eso vale tanto para los libros de caballería como para los libros científicos. Tal vez la libertad moderna consiste esencialmente en poder elegir entre varios conceptos o «libros» del mundo, y su precio está en la conciencia de la arbitrariedad de ellos.

\section{BIBLIOGRAFÍA CITADA}

Alonso, Dámaso (2003). «Prólogo», en Martín de Riquer, Para leer a Cervantes. Barcelona: Acantilado, pp. 11-17.

Aristóteles (1987). Acerca de la generación y la corrupción / Tratados breves de historia natural. Madrid: Gredos.

Aristóteles (1996). Acerca del cielo / Meteorológicos, Madrid, Gredos.

Bacon, Francis (1620). Instauratio Magna. Londini: Joannes Billius.

Beer, Gillian (1983). Darwin's plots: evolutionary narrative in Darwin, George Eliot and nineteenth-century-fiction. London/Boston: Routledge.

Blumenberg, Hans (1997 [1960]). Paradigmen zu einer Metaphorologie. Frankfurt am Main: Suhrkamp.

Castro, Américo (1973). El pensamiento de Cervantes, Barcelona, Noguer.

Cervantes, Miguel de (2014). Don Quijote de la Mancha. Francisco Rico (ed.). Madrid: Santillana.

Copérnico, Nicolás (1543). De revolutionibus orbium coelestium. Norimbergae: Iohan Petreium.

Dicter (Diccionario de la ciencia y de la técnica del Renacimiento) (2002-2013). María Jesús Mancho (dir.). Salamanca: Ediciones Universidad. [dicter.usal.es].

Enzensberger, Hans-Magnus (2002). Die Elixiere der Wissenschaft. Frankfurt am Main: Suhrkamp.

Fernández de Enciso, Martín (1530 [1519]). Suma de Geographía, Sevilla: Juan Cromberger. Galileo Galilei (1610). Siderius nuncius. Venetiis: Thomam Baglionum.

Grassi, Ernesto (1980). Rhetoric as philosophy. The humanist tradition. London: Pennsylvania State University Press.

Koyré, Alexandre (1979). Del mundo cerrado al universo infinito. Madrid: S.A.

Kuhn, Thomas S. (1996 [1962]). The structure of scientific revolutions. Chicago: University of Chicago Press.

López Piñero, José María (ed.) (2002). Historia de la ciencia y de la técnica en la Corona de Castilla. Tomo III: siglos XVI y XVII, Salamanca: Junta de Castilla y León.

Maravall, José Antonio (2006). Utopía y contrautopía en el Quijote. Madrid: Visor.

Medina, Pedro de (1545). Arte de navegar, Valladolid: Francisco Fernández de Córdoba.

Muñoz, Jerónimo (1573). Libro del nuevo cometa. Valencia: Pedro de Huete.

Navarro Brotons, Víctor (2005). «La geografía y la cosmografía en la época de El Quijote», en La ciencia y el Quijote. José Manuel Sánchez Ron (ed.). Barcelona: Crítica, pp. 13-21.

Pacheco de Narvaez, Luis (1600). Libro de las grandezas de la espada. Madrid: Juan Iñiguez de Lequerica.

Pérez de Oliva, Fernán (2008). Diálogo de la dignidad del hombre. Razonamientos. Ejercicios. María Luisa Cerrón Puga (ed.). Madrid: Cátedra.

Plutarco (2010). Vidas Paralelas: Alejandro-César. Madrid: Gredos.

Riquer, Martín de (2003). Para leer a Cervantes, Barcelona: Acantilado. 
Sánchez Ron, José Manuel (ed.) (2005). La ciencia y el Quijote. Barcelona: Crítica.

Schmelzer, Felix (2015). La retórica del saber. El prólogo de los tratados matemáticos en lengua española (1515-1600). New York: IDEA.

Spitzer, Leo (1955). «Perspectivismo lingüístico en el Quijote», en Lingüistica e historia literaria, Madrid: Gredos, pp. 135-187.

Recibido: 21 de agosto de 2015

Aceptado: 20 de mayo de 2016 